\title{
AEROSOL OBSERVATION USING MULTI-WAVELENGTH MIE-RAMAN LIDARS OF THE AD-NET AND AEROSOL COMPONENT ANALYSIS
}

\author{
Tomoaki Nishizawa $^{1 *}$, Nobuo Sugimoto ${ }^{1}$, Atsushi Shimizu ${ }^{1}$, \\ Itsushi Uno ${ }^{2}$, Yukari Hara ${ }^{2}$, and Rei Kudo ${ }^{3}$ \\ ${ }^{I}$ National Institute for Environmental Studies, 16-2 Onogawa, Tsukuba, 305-8506, Japan, \\ *nisizawa@nies.go.jp \\ ${ }^{2}$ Research Institute for Applied Mechanics, Kyushu University, 6-1 Kasugakoen, Kasuga 816-8580, \\ Japan \\ ${ }^{3}$ Meteorological Research Institute, Japan Meteorological Agency, 1-1 Nagamine, Tsukuba 305-0052, \\ Japan
}

\begin{abstract}
We deployed multi-wavelength Mie-Raman lidars (MMRL) at three sites of the AD-Net and have conducted continuous measurements using them since 2013. To analyze the MMRL data and better understand the externally mixing state of main aerosol components (e.g., dust, sea-salt, and black carbon) in the atmosphere, we developed an integrated package of aerosol component retrieval algorithms, which have already been developed or are being developed, to estimate vertical profiles of the aerosol components. This package applies to the other ground-based lidar network data (e.g., EARLINET) and satellite-borne lidar data (e.g., CALIOP/CALIPSO and ATLID/EarthCARE) as well as the other lidar data of the AD-Net.
\end{abstract}

\section{INTRODUCTION}

To assess the effects of aerosols on the atmospheric environment and climate, it is essential to observe the optical and microphysical properties and chemical composition of aerosols and to understand their spatial distribution and temporal variation. We deployed multi-wavelength Mie-Raman lidars (MMRL) at the Hedo $\left(26.87^{\circ} \mathrm{N}, \quad 128.25^{\circ} \mathrm{E}\right), \quad$ Fukuoka $\left(35.52^{\circ} \mathrm{N}\right.$, $\left.130.47^{\circ} \mathrm{E}\right)$, and Toyama $(36.70 \mathrm{~N}, 140.12 \mathrm{E})$ (Fig. 1), which are the AD-Net [1] observation sites in Japan and have conducted continuous measurements in collaboration with Kyushu University (Japan) and the University of Toyama (Japan) since 2013. The main objectives of these observations are to evaluate the extinction coefficients of major aerosol components (dust (DS), sea-salt
(SS), black carbon (BC), and air pollution particles without $\mathrm{BC}(\mathrm{AP})$ ) in the atmosphere from the MMRL measurements, to provide the aerosol component data for data assimilation analyses as the input data, and to contribute to evaluating the emission of the aerosol components and building aerosol-assimilated data for each region of East Asia.

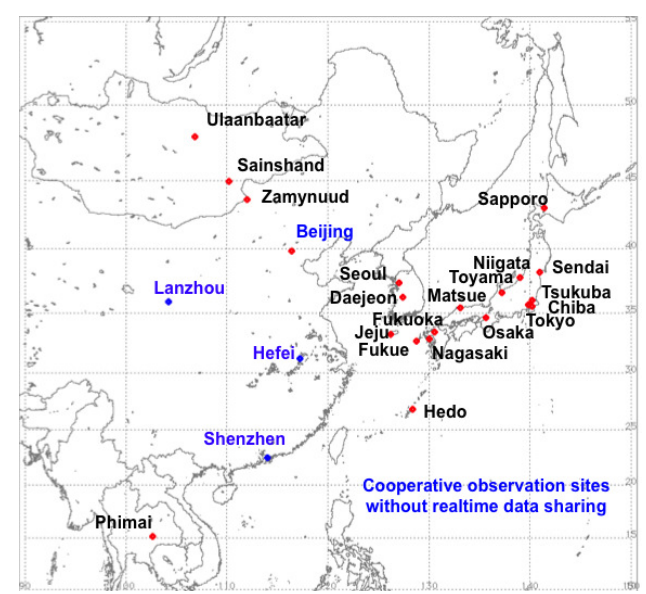

Fig. 1 Observation sites in AD-Net

In this paper, we report the MMRL system and analysis results of aerosol optical properties derived from the MMRL measurements (Section 2). Furthermore, we developed an algorithm to retrieve extinction coefficients of the aerosol components using the MMRL data. We report the developed algorithm and the primary results (Section 3). 


\section{AEROSOL OBSERVATION USING MULTI-WAVELENGTH MIE-RAMAN LIDARS (MMRL)}

MMRL provides particle extinction $(\alpha)$ and backscatter $(\beta)$ coefficients at 355 and $532 \mathrm{~nm}$, particle depolarization ratio $(\delta)$ at 355 and $532 \mathrm{~nm}$, and the attenuated backscatter coefficient at $1064 \mathrm{~nm}$ (i.e., $2 \alpha(355,532)+3 \beta$ $(355,532,1064)+2 \delta(355,532)$ data $)$. The details of the system, method of retrieving aerosol optical properties, and the measurement and retrieval accuracies are given in Nishizawa et al. [2]. Here, we present the outlines.

The MMRL system employs a commercial compact Nd:YAG laser with second-harmonic and third-harmonic generators and a rigid biaxial configuration. Backscattered light is collected with a vertically mounted telescope. The collected light is split among the receivers at 355, 387, 532, 607, and 1064nm using dichroic beam splitters. At 532 and $355 \mathrm{~nm}$, the co-polarized and cross-polarized components of the total backscatter light split with a cube polarizer are detected using two PMTs. At 607 and 387nm, nitrogen Raman backscatter signals are detected using a PMT. At $1064 \mathrm{~nm}$, the total backscatter light is detected using an APD. Band-path filters are set for all the detectors in order to reduce contamination from background light. We conducted photon-counting measurements for Raman backscatter and analog measurements for elastic backscatter. No Raman channel data are available in the daytime due to strong sunlight. The lidar continuously follows a work cycle of $5 \mathrm{~min}$ on and $10 \mathrm{~min}$ off in order to maintain laser life. The signals are accumulated for 3000 laser shots, corresponding to $5 \mathrm{~min}$, in the $7.5 \mathrm{~m}(6 \mathrm{~m})$ range bin up to $30 \mathrm{~km}(24 \mathrm{~km})$ for Raman (elastic) backscatter signals, and recorded every 15 min for both elastic and Raman signals.

The aerosol optical properties (i.e., $\alpha_{\mathrm{a}}, \beta_{\mathrm{a}}$, and $\delta_{\mathrm{a}}$ ) are derived every $30 \mathrm{~m}$ and $15 \mathrm{~min}$ using a conventional retrieval method [e.g., 3]. We first average the measured signals over every $30 \mathrm{~m}$ range to match the vertical resolution between the Raman signal data and the elastic signal data. Next, we identify an aerosol-rich layer as well as a molecule-rich layer and a cloud-rich layer using the averaged $\beta_{1064}[$ e.g., 4]. To remove data contaminated by clouds or rain and to improve the signal-to-noise ratio (SNR) of the measured signals, we apply a moving average in window ranges (half range) of $30 \mathrm{~m}$ vertical and $45 \mathrm{~min}$ temporal to the signal data after we remove the data at and above any slab-layer identified as a cloud or rain layer (Fig. 2). $\alpha_{\mathrm{a}}, \beta_{\mathrm{a}}$, and $\delta_{\mathrm{a}}$ are then derived using the moving-averaged data. Finally, we also apply a moving average in window ranges (half width) of $60 \mathrm{~m}$ vertical resolution and 30min temporal resolution to the derived $\alpha_{a}$, $\beta_{\mathrm{a}}$, and $\delta_{\mathrm{a}}$ to reduce the impact of signal noise (Fig. 3). The lidar ratio of aerosols $\left(S_{a}\right)$, defined as the extinction-to-backscatter ratio $\left(S_{a}=\alpha_{a} / \beta_{a}\right)$, is derived using the moving-averaged $\alpha_{a}$ and $\beta_{a}$.

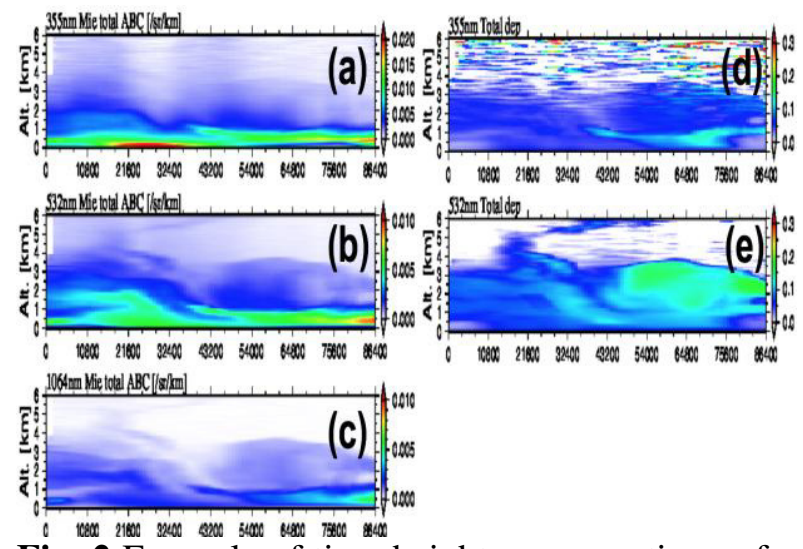

Fig. 2 Example of time-height cross sections of moving-averaged attenuated backscatter coefficients at 355nm (a), 532nm (b), and $1064 \mathrm{~nm}$ (c), and total depolarization ratio at $355 \mathrm{~nm}$ (d) and $532 \mathrm{~nm}$ (e) after removing the data contaminated by clouds or rain measured at Fukuoka on 21 Mar. 2015.
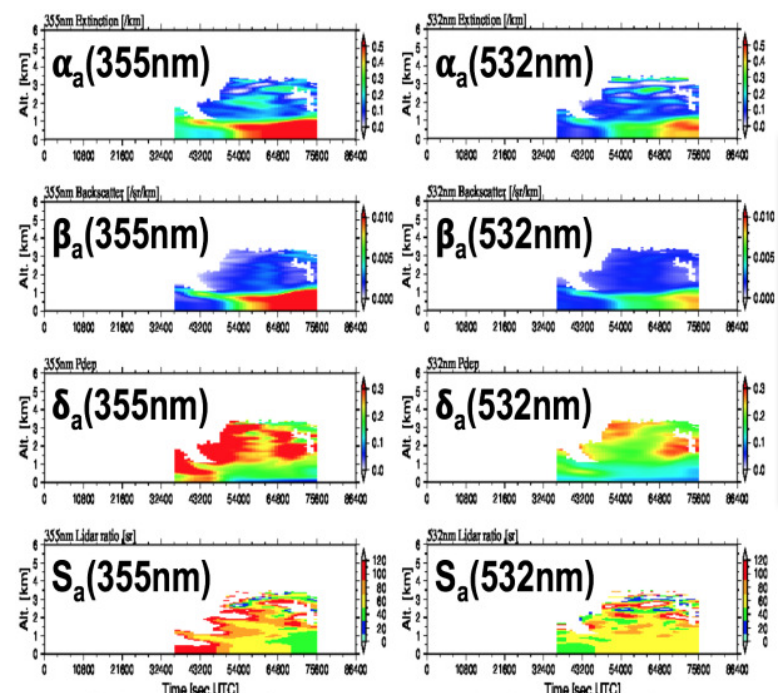

Fig. 3 Example of time-height cross sections of derived $\alpha_{\mathrm{a}}, \beta_{\mathrm{a}}, \delta_{\mathrm{a}}$, and $\mathrm{S}_{\mathrm{a}}$ at 355 and $532 \mathrm{~nm}$ measured at Fukuoka on 21 Mar. 2015. 
Using the $\alpha_{\mathrm{a}}, \beta_{\mathrm{a}}, \delta_{\mathrm{a}}$, and $\mathrm{S}_{\mathrm{a}}$ data at Fukuoka from January 2015 to May 2015, we characterized aerosol optical properties for several remarkable aerosol events (e.g., air pollution rich or mineral dust rich events) [5]. The aerosol events were basically extracted from ground-based sampling and chemical measurements. The mean $S_{a}$ for air pollution cases (5-day data) was $57 \pm 4 \mathrm{sr}$ at $355 \mathrm{~nm}$ and $53 \pm 8 \mathrm{sr}$ at $532 \mathrm{~nm}$. The mean $\delta_{\mathrm{a}}$ was $4 \pm 1 \%$ at $355 \mathrm{~nm}$ and $6 \pm 2 \%$ at $532 \mathrm{~nm}$. These values are consistent with previous observations using lidar for air pollution events [e.g., 6, 7]. For mineral dust cases (6day data), the mean $S_{a}$ was $50 \pm 7 \mathrm{sr}$ at $355 \mathrm{~nm}$ and $54 \pm 9 \mathrm{sr}$ at $532 \mathrm{~nm}$; The mean $\delta_{\mathrm{a}}$ was $13 \pm 8 \%$ at $355 \mathrm{~nm}$ and $16 \pm 6 \%$ at $532 \mathrm{~nm}$. These values are close to those for the "Dusty-mixture" categorized in Illingworth et al. [8] and imply mixture of mineral dust with air pollution particles. We will improve this aerosol characterization analysis by increasing data samples for noteworthy aerosol events.

\section{AEROSOL COMPONET RETRIEVAL USING AD-NET LIDARS}

We developed some algorithms to identify the aerosol components and retrieved their vertical distributions in an extinction coefficient assuming an external mixture of some aerosol components and prescribing their microphysical and optical properties from AD-Net lidar measurements. Sugimoto et al. [9] used depolarization ratios for classifying non-spherical DS and spherical aerosols (i.e., $\mathrm{AP}+\mathrm{BC}+\mathrm{SS}$ ) and retrieved their extinction coefficients using $1 \beta(532)+1 \delta(532)$ lidar data $(1 \beta+1 \delta$ method $)$. Nishizawa et al. [10] used spectral (color) ratios of backscatter coefficients for classifying large aerosols (e.g., SS and DS) and small aerosols (e.g., AP and BC) as well as depolarization ratio and retrieved DS, SS, and small aerosols (i.e., $\mathrm{AP}+\mathrm{BC})$ using $2 \beta(532,1064)+1 \delta(532)$ data $(2 \beta+1 \delta$ method). Nishizawa et al. [11] used lidar ratios for classifying $\mathrm{BC}$ with strong light absorption and weak light absorption aerosols (e.g., $\mathrm{SS}, \mathrm{AP})$ as well as the depolarization ratio, and retrieved DS, BC, and weak light absorption aerosols (i.e., $\mathrm{AP}+\mathrm{SS}$ ) using $1 \alpha+1 \beta+1 \delta$ data at 532 or $355 \mathrm{~nm}(1 \alpha+1 \beta+1 \delta$ method $)$. Nishizawa et al. [2] used all the depolarization ratio, color ratio, and lidar ratio and retrieved $\mathrm{DS}, \mathrm{SS}, \mathrm{BC}$, and AP using $1 \alpha(532)+2 \beta(532,1064)+$ $1 \delta(532)$ data $(1 \alpha+2 \beta+1 \delta$ method).

\subsection{Algorithm using all the seven MMRL channels $(2 \alpha+3 \beta+2 \delta$ method)}

The MMRL has seven channels (i.e., $2 \alpha+3 \beta+$ $2 \delta$ data). For developing the $1 \alpha+2 \beta+1 \delta$ method, we are developing an algorithm to retrieve mode-radii $\left(\mathrm{R}_{\mathrm{m}}\right)$ of $\mathrm{DS}$, AP, and SS using color ratios of extinction, backscatter and depolarization ratio as well as extinction coefficients of the four aerosol components $(\sigma)$ (DS, SS, BC, and AP). In this algorithm, we assume that (1) the size distribution for each aerosol component is log-normal; (2) DS is spheroidal and the others are spherical; and (3) the refractive index and standard deviation of DS, SS, AP, and BC are fixed and the mode radius of $\mathrm{BC}$ are fixed (see Table 1). This estimation of the seven parameters (i.e., $\sigma$ for DS, SS, BC, and AP and $\mathrm{R}_{\mathrm{m}}$ for DS, SS, and AP) using seven channel lidar data amounts to solving seven-order non-linear simultaneous equations, and thus we use the GaussNewton method with the line search based on the least-square method [2]. We will report the primary results in the conference.

\subsection{Integrated package of aerosol component retrieval algorithms}

We developed an integrated package of aerosol component retrieval algorithms, which includes developed algorithms (i.e., $2 \beta+1 \delta, 1 \alpha+1 \beta+1 \delta$, and $1 \alpha+2 \beta+1 \delta$ methods) and a new developed one (i.e., $2 \alpha+3 \beta+2 \delta$ method), to estimate vertical profiles of the aerosol components. In this package, the same analytical method (i.e., GaussNewton method with the line search) is used for all retrievals and the optical model of each aerosol component consistent for all the retrieval methods are used. The primary results are depicted in Fig. 4. The $2 \beta+1 \delta$ method was applied to $2 \beta(532,1064)+1 \delta(532)$, the $1 \alpha+1 \beta+1 \delta$ method was applied to $1 \alpha(532)+1 \beta(532)+1 \delta(532)$, and the $1 \alpha+2 \beta+1 \delta$ method was applied to, $1 \alpha(532)+2 \beta(532,1064)+1 \delta(532)$ of the MMRL data at Fukuoka on 21 Mar. 2015. Note that the $2 \beta+1 \delta$ method can apply to daytime data because it does not use Raman channel data. The optical model for each aerosol component used in this estimation is given in Table 1. When the $2 \alpha+3 \beta+2 \delta$ method is applied, the mode-radii for 
DS, SS, and BC are estimated (not fixed).

This package applies to the other ground-based lidar network data (e.g., EARLINET) and satellite-borne lidar data (e.g., CALIOP/CALIPSO and ATLID/EarthCARE) as well as the other lidar data of the AD-Net.

Table 1 Optical model for each aerosol component used in the component retrieval.

\begin{tabular}{|c|c|c|c|c|}
\hline & $\mathbf{A P}$ & DS & BC & SS \\
\hline $\begin{array}{c}\text { Effective ra- } \\
\text { dius }[\mu \mathrm{m}]\end{array}$ & 0.11 & 1.44 & 0.04 & 2.1 \\
\hline $\begin{array}{l}\text { Standard } \\
\text { deviation }\end{array}$ & 1.6 & 2.2 & 2.0 & 2.1 \\
\hline $\begin{array}{c}\text { Refractive } \\
\text { index } \\
(\mathbf{5 3 2 n m}) \\
\end{array}$ & $\begin{array}{c}1.43 \\
3 \cdot 10^{-3}\end{array}$ & $\begin{array}{c}1.51 \\
3 \cdot 10^{-3}\end{array}$ & $\begin{array}{l}1.75 \\
0.44\end{array}$ & $\begin{array}{l}1.37 \\
4 \cdot 10^{-9}\end{array}$ \\
\hline 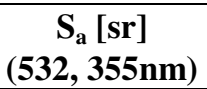 & $\begin{array}{l}52, \\
70\end{array}$ & $\begin{array}{l}47 \\
79\end{array}$ & $\begin{array}{l}98, \\
97\end{array}$ & $\begin{array}{l}19, \\
16\end{array}$ \\
\hline $\begin{array}{c}\boldsymbol{\delta}_{\mathrm{a}} \\
(532,355 \mathrm{~nm}) \\
\end{array}$ & $\begin{array}{l}0.02, \\
0.02\end{array}$ & $\begin{array}{l}0.30, \\
0.28 \\
\end{array}$ & $\begin{array}{l}0.02, \\
0.02\end{array}$ & $\begin{array}{l}0.02, \\
0.02\end{array}$ \\
\hline $\begin{array}{c}\text { Backscatter } \\
\text { color ratio } \\
(1064 / 532 \\
\text { 355/532) }\end{array}$ & $\begin{array}{c}0.35 \\
1.68\end{array}$ & $\begin{array}{c}0.98 \\
0.57\end{array}$ & $\begin{array}{c}0.24, \\
1.74\end{array}$ & $\begin{array}{c}0.66, \\
1.13\end{array}$ \\
\hline
\end{tabular}

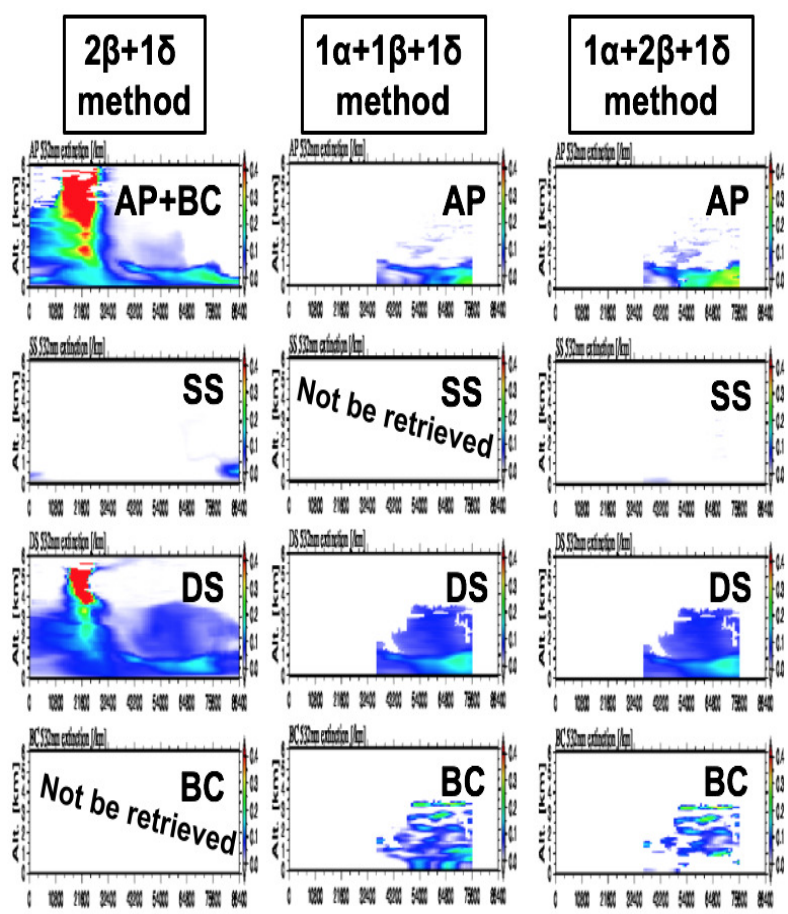

Fig. 4 Example of time-height cross sections of $\sigma$ at $532 \mathrm{~nm}$ retrieved by the $2 \beta+1 \delta$ method (left column), $1 \alpha+1 \beta+1 \delta$ method (middle column), and $1 \alpha+2 \beta+1 \delta$ method using data measured at Fukuoka on 21 Mar., 2015.
EarthCARE is an ongoing aerosol, cloud, and radiation observation project conducted by ESA, JAXA, and NICT. A $355 \mathrm{~nm}$ high-spectral resolution lidar (HSRL) ATLID providing $1 \alpha+1 \beta+1 \delta$ at $355 \mathrm{~nm}$ and multi-spectral imager MSI are aboard EarthCARE sattelite [8]. We are developing an algorithm to estimate extinction coefficients of BC, SS, DS, and AP from the ATLID and MSI measurements in collaboration with JAXA. We are also improving AD-Net by introducing multi-wavelength Raman lidars and HSRLs with measurement capability at $355 \mathrm{~nm}$ to assist with the EarthCARE validation observation. The data analysis of a multi-channel lidar with more channels than the ATLID is useful for validating the ATLID-derived extinction coefficients of aerosol components because the algorithm using the multi-channel lidar data makes fewer assumptions and is more accurate. This developed package will be used for this validation study.

\section{ACKNOWLEDGEMENTS}

This research was partly supported by a Grantin-Aid for Scientific Research (25220101) from the Japan Society for the Promotion of Science (JSPS) and the first EarthCARE algorithm and validation Research Announcement from JAXA.

\section{References}

[1] Shimizu, A., et al., 2016: Opt. Eng., 56, 031219, doi:10.1117/1.OE.56.3.031219.

[2] Nishizawa, T., et al., 2017: J. Quant. Spec. Rad. Trans., 188, 79-93.

[3] Xie, C., et al., 2008: Appl. Opt., 47, 49454951.

[4] Shimizu, A., et al., 2004: J. Geophys. Res., 109, D19S17, doi:10.1029/2002JD003253.

[5] Hara, Y., et al., 2017: J. Quant. Spec. Rad. Trans., 188, 20-27.

[6] Noh Y. M., et al., 2018: Atmos. Env., 42, 2208-2224

[7] Muller D., et al., 2007: J. Geophys. Res., 112, D16202, doi:10.1029/2006JD008292.

[8] Illingworth, A. J., et al., 2016: BAMS, doi:10.1175/BAMS-D-12-00227.1

[9] Sugimoto, N., et al., 2003: Geophys. Res. Let., 30, 1640, doi:10.1029/2002GL016349.

[10] Nishizawa, T., et al., 2011: J. Quant. Spec. Rad. Trans., 112, 254-267.

[11] Nishizawa, T., et al., 2008: Trans. Geosci. Rem. Sens., 41, 1743-54.

[12] Nishizawa, T., 2013: J. Rem. Sens. Soc. Jap., 33, 367-376 (in Japanese) 